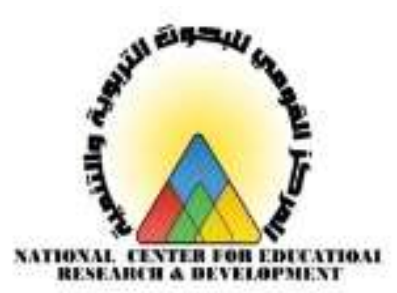

\title{
أثر استخدام خرائط المفاهيم في تنمية هفاهيم التنور المائي لدى طلاب الصف الأول الثانوي
}

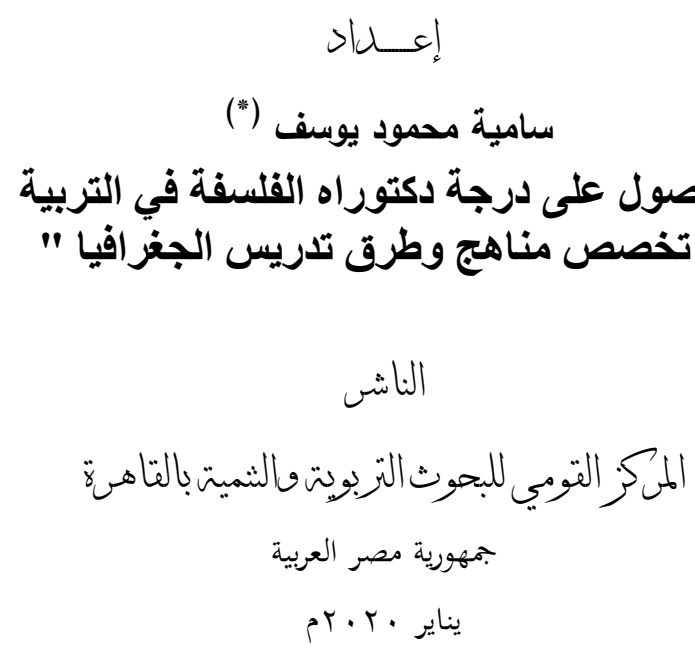

إثــــ

أ.د /عباس راغب علام

أستاذ المناهج وطرق تدريس الدراسات راعل علات

الاجتماعية بكلية التربية جامعة بور سعيد
أ.د / أحمد إبراهيم شلبي

أستاذ المناهج وطرق تدريس الجغرافيا

بكلية التربية جامعة عين شمس تلني

\section{د / محمد محمد أحمد حال}

مدرس المناهج وطرق تدريس الدراسات الاجتماعية

بكلية التربية جامعة بور سعيد

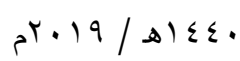




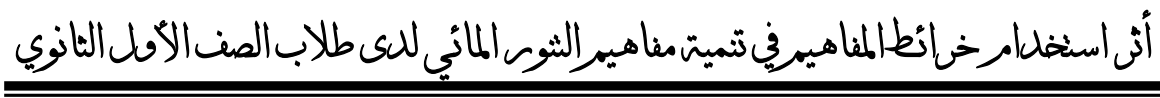

. Yาร.

البحث التريوي 


\section{أثر استخام خرانط المفاهيم في تنمية مغاميه التنور الالائي لاى طلاب الصغ الأول الثانوي blu_es_}

سامية محمود يوسف

\section{هستخلص البحث :}

تعرف أثز استخدام استراتيجية خرائط المفاهيم على تتمية بعض مفاهيم التتور المائي ، استخدمت الباحثة المنهج الوصفي عند تتاول الإطار النظري، والمنهج شبه التجريبي عند التطبيق الميداني. ويمكن تلخيص أهم النتائج التي توصل إليها البحث في أن: استراتيجية خرائط المفاهيم كانت فعالة من خلال نتائج أداة البحث، وأن هناك فرق دال إحصائيا بين متوسطات درجات الطالبات مجموعة البحث في اختبار المفاهيم لصالح التطبيق البعدي للاختبار ، كما توصل البحث الحالي إلى لى افتقار طالبات الصف الاول الثانوي لبعض مفاهيم التتور المائي ، والتوصل إلى قائمة بالمفاهيم اللازمة لطلاب الصف الأول الثانوي بما يحقق التتمية الفعالية

لدينهم.

الكلمات المفتاحية :

- استراتيجية خرائط المفاهيم. - مفاهيم التتور المائي. - ماءئ - طلاب الصف الأول الثانوي. 


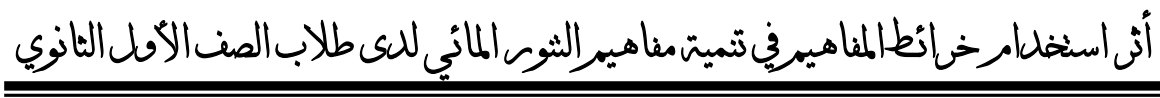

. Y77.

البحث التريوي 


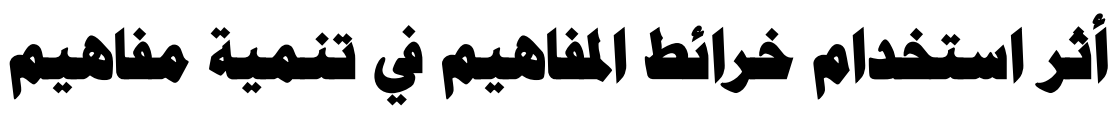 التنور المائي لدى طلاب الصف الأول الثانوي إعـاد}

سامية محمود يوسف

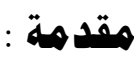

يعتبر الماء شريان الحياة، وسر تدفقها وبقائها، وبدونه تتوقف الحياة بما

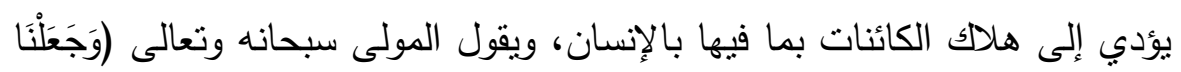

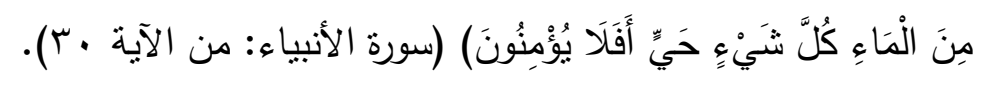

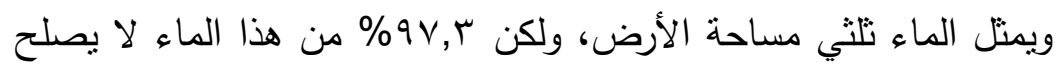

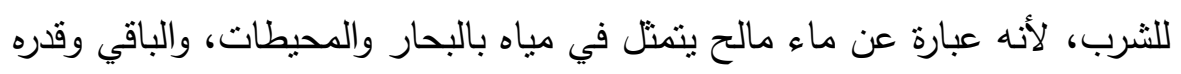

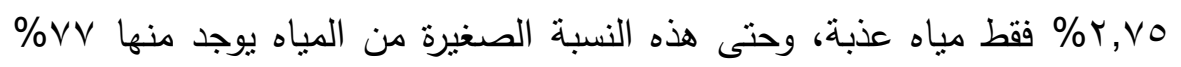

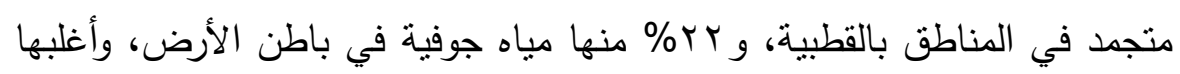

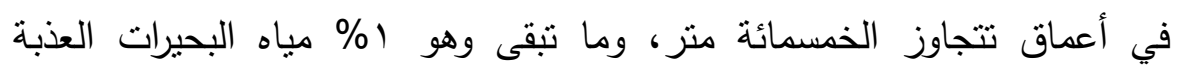

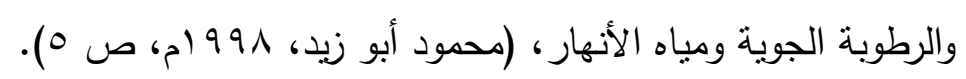

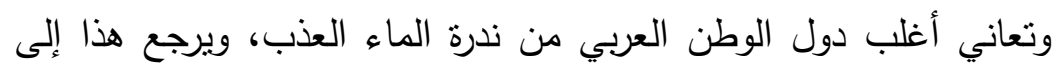

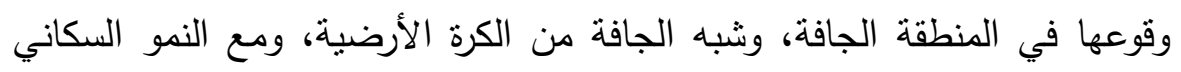

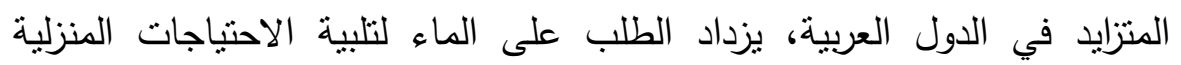

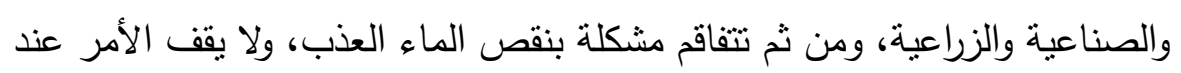

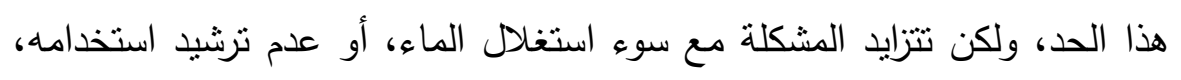

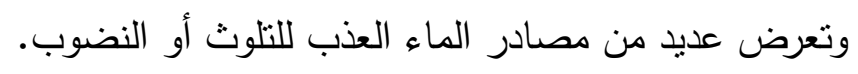




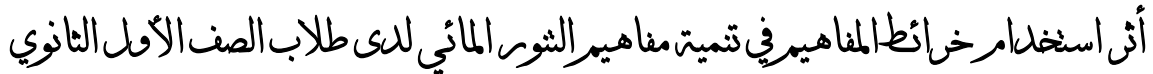

وقد أثرت هذه المشكلات على نصيب الفرد من الماء بالوطن العربي،

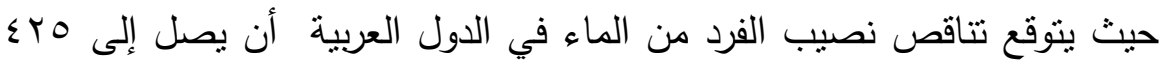

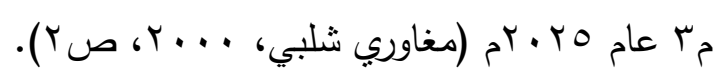

وتعتبر قضية المحافظة على الماء العذب وترشيد استخدامه إحدى القضايا التي يمكن أن تقوم التربية بدور كبير في مواجتها، من خلال ما يسمى بالتتور

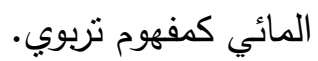

تعتبر المدرسة المؤسسة الاجتماعية الأولى في أي مجتمع والتي يعول

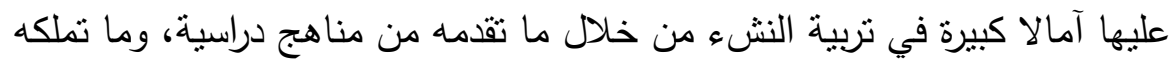

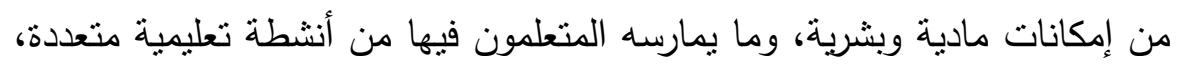

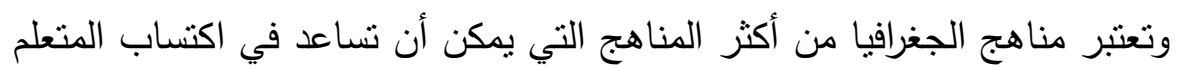

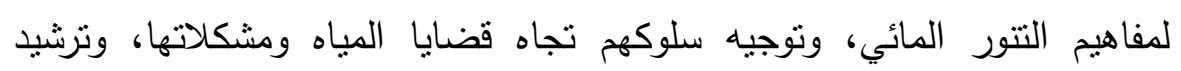

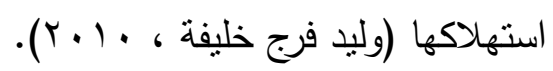

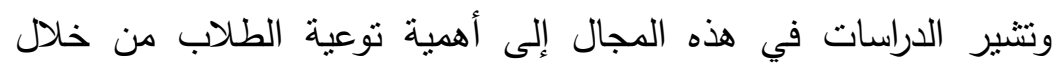
المناهج الدراسية بقضايا التلوث البيئي والماء (Madalla, 2004)، كما أكدت فئل عديد من الدراسات

تؤكد الهناهج الحديثة على تدريس المفاهيم بدلاً من الاهتمام بالحقائق

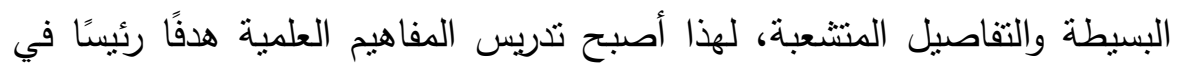

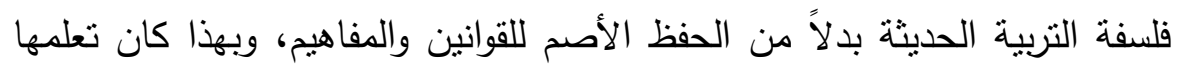

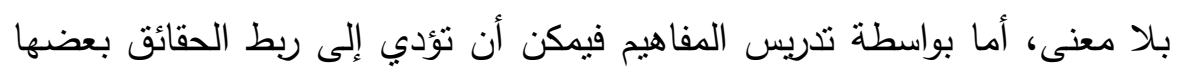

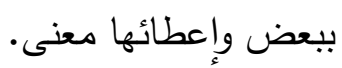

وجاءت الرغبة الكبيرة في تحسين العملية التعليمية من خلال

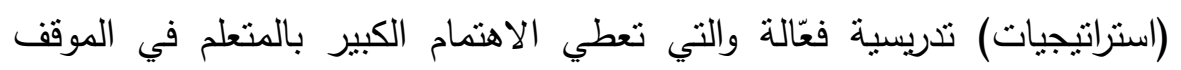


التعليمي، لذلك أثمرت الجهود إلى مساعدة المتعلم في نطوير (استراتيجيات) منها

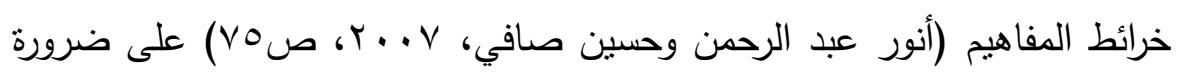

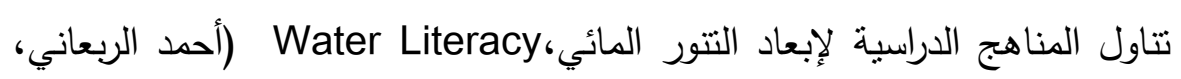
(r...o

تعد خرائط المفاهيم إحدى التطبيقات التربوية لنظرية أوزوبل (التعلم ذي

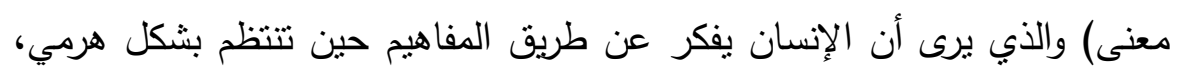

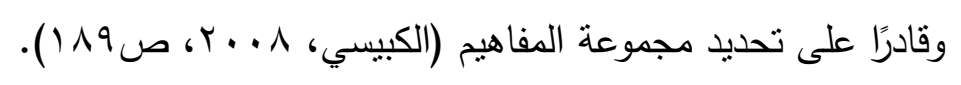

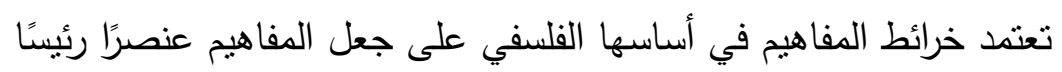

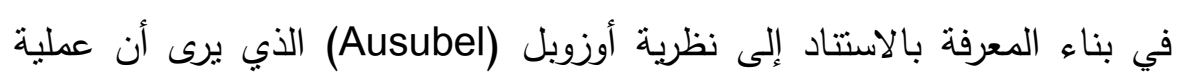

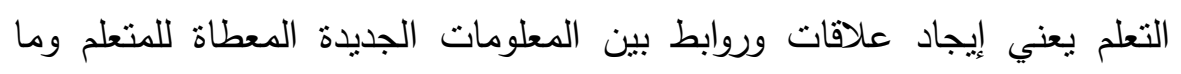

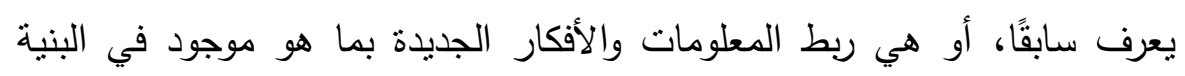

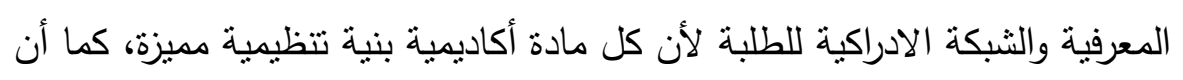
لكل فرد بنية معرفية تمييزه عن غيره (Novak, p , 1990). وترى الباحثة أن ربط المعلومات السابقة بالمعلومات الجديدة ربطًا فعليًا،

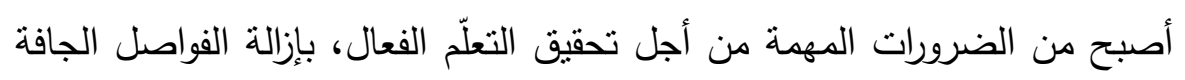

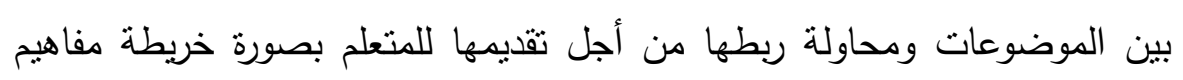

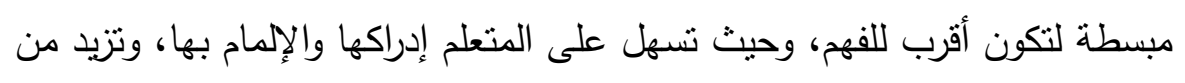

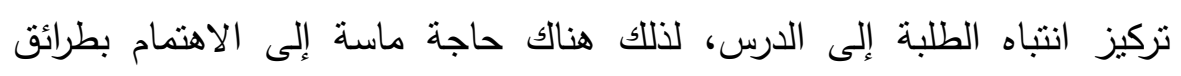

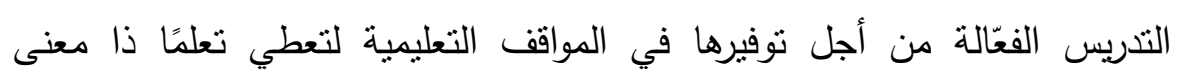
للمتعلم.

الإحساس بالمشكلة : نولد الإحساس بمشكلة هذا البحث من خلال :

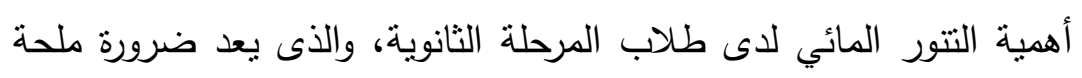
واتجاهًا عالميًا للحفاظ على المياه وترشيد استهلاكها واستثمارها. 


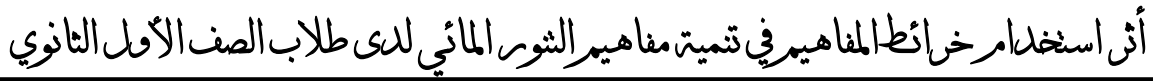

ما نراه أمام ناظرينا من سلوكيات غير رشيدة في التعامل مع المباه العذبة،

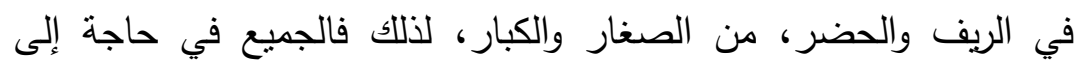
تغيير أسلوب استخدام المياه، وإلى اكتساب أنماط الوعى والاتجاهات

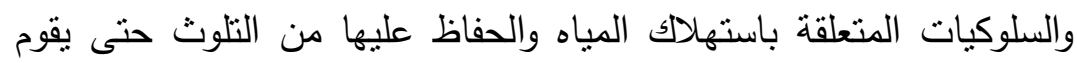
كل بدوره ويتحمل المسئولية، ويحافظ على هذه النعمة المهداة إلينا من الله

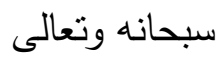

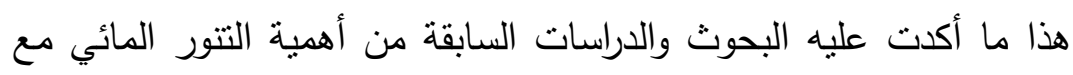

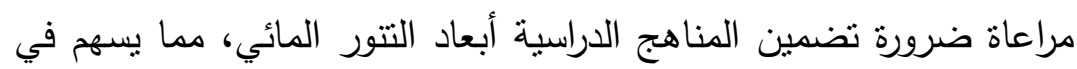
تحسين علاقة المتعلم بالبيئة المائية وبالتالي بساعد علي نعديل سلوك

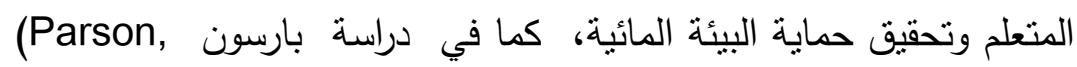

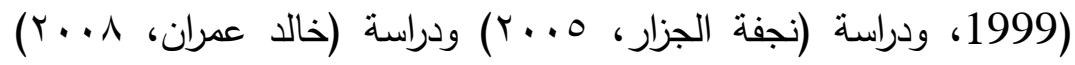

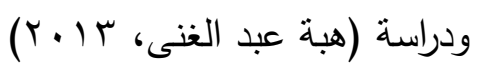

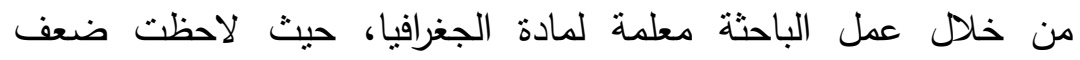
المفاهيم المائية لاى الطلبة مشكلة البحث وأسئلته:

اتضح مما سبق أن قضية الماء تعتبر إحدى القضايا البيئية والتتموية الهامة

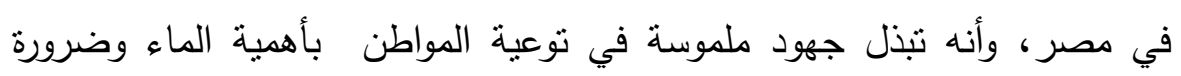
ترشيد استخدامه والمحافظة عليه من التلوث، وذلك من خلال المؤسسات التربويةالنظامية وغير النظامية- وتمثل المرحلة الثانوية إحدى المؤسسات التربوية النظامية

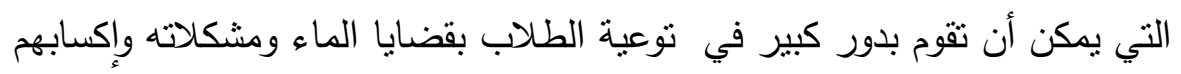

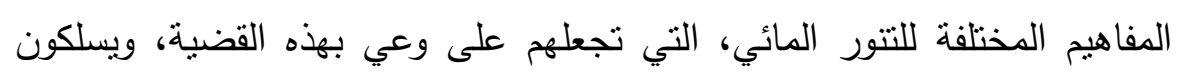

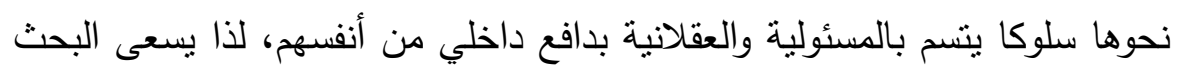

$$
. Y V \cdot
$$


الحالي إلى تعريف أثز خرائط الدفاهيم في تتمية التتور المائي لدى الطلاب، وينطلب هذا الإجابة عن الأسئلة التالية:

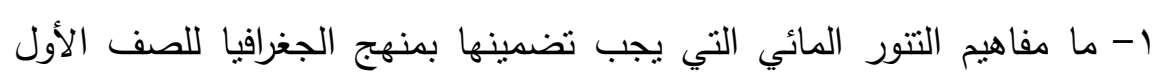
الثانوي ؟ أبان

ץ- ما أثر استخدام خرائط المفاهيم في تتمية مفاهيم التتور المائي ؟ أهمية البحث : تكمن أهمية هذا البحث فيما يلي: ا. تحديد بعض مفاهيم التتور المائي التي يجب تضمينها بمنهج الجغرافيا في

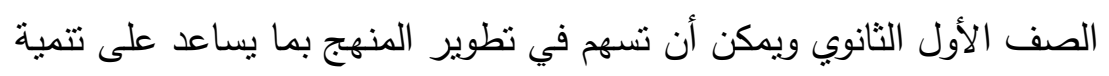

$$
\text { اتتور المائي لدى الطلاب. }
$$

r. تعرف مستوى التتور المائي لدى الطلاب يمكن أن بساعد المسئولين على تعرف نوعية السلوك المستقبلي لهؤلاء الطلاب نحو الماء، ومن ثم تدعيم السلوكيات المرغوبة ومحاولة تعديل أو تلافي آثار السلوكيات غير المرغوبة.

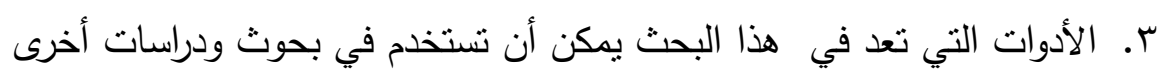

$$
\begin{aligned}
& \text { مشابهة أو يعد على غرارها أداوت أخرى. } \\
& \text { هـدف البحث : يهدف البحث الحالي إلى تعرف لئل }
\end{aligned}
$$

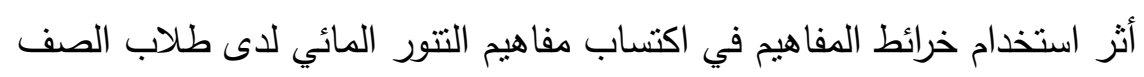
الأول الثانوي.

\section{فرض البحث :}

1- يوجد فرق ذو دلالة إحصائية عند مستوى (0.، ·) ) بين متوسطي درجات طلاب عينة البحث قبليًا وبعديًا في الاختبار التحصيلي لدفاهيم التتور المائي لصالح التطبيق البعدي. . TVI. 


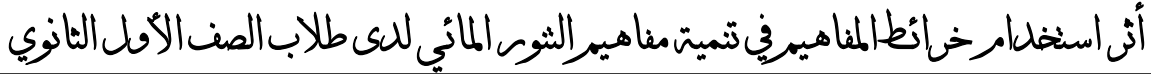

\section{هصطات البمثث:}

Concept Maps : : خرائط المفاهيم

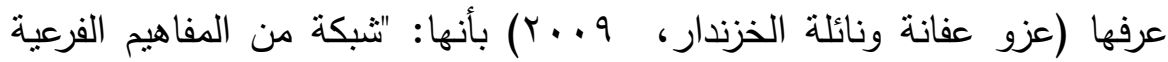
التي تتدمج تحت مفاهيم عامة من خلال علاقات هرمية بين المفاهيم الأكثر عمومية".

- التعريف الاجرائي: هي مخططات توضح العلاقات بين المفاهيم الجغرافية الرئيسية والفرعية المتضمنة في موضوع البحث، بواسطة أسهر وكلمات

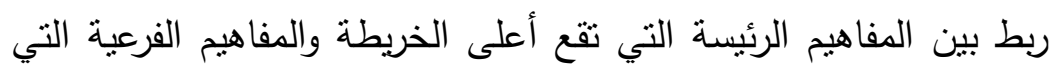
تتدرج تحتها، بهذف معرفة أثرها في اكتساب مفاهيم التتور المائي لاى طالبات مجموعة البحث ومساعدتهن على فهم العلاقات بين المفاهيم وتسهيل تطبيقها وإدراكها.

Water Literacy : التنور المائي

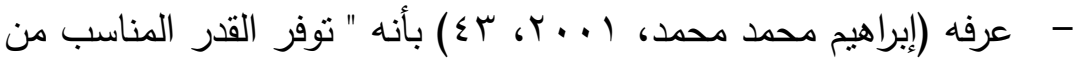
الحقائق والمفاهيم العلمية المرتبطة بالمياه وخصائصها ومواردها، والمشكلات الناجمة عن نقصها وتلوثها، والتعامل الحكيم والاستعلال الراشد للموارد المائية، والذى يتضمن (أ- البعد المعرفي بهابـ البعد

$$
\text { السلوكي ج- البعد الوجداني). }
$$

- يُعرف إجرائيًا في هذا البحث بأنه: "امتلالك الطالب مجموعة من الحقائق والمفاهيم والقيم والاتجاهات العلمية المرتبطة بالمياه وخصائصها ومواردها والمشكلات الناجمة عن نقصها وتلوثها، التي تمكنه من أن يمارس سلوكًا رشيدًا تجاه الموارد المائية، ويساهم في إيجاد حلول للمشكلات المائية التى تواجه مجتمعه. ويستدل على ذلك من خلال 
استجابة الطلاب على مقياس التتور المائي واختبار تحصيلي لهفاهيم

$$
\text { التتور المائي الذى يقيس : }
$$

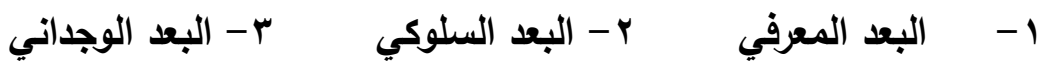

الخلفيسة النظـريسة والدراسات السابقة :

خرائط المفاهيم

الأساس الفلسفي لخرائط المفاهيم والنظريات التي بنيت عليها: إنّ خرائط

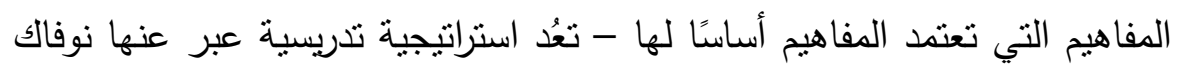
وكوين ( Gowin and Novak " ( بأنها وسيلة لترتيب المعلومات نساعد المتعلم

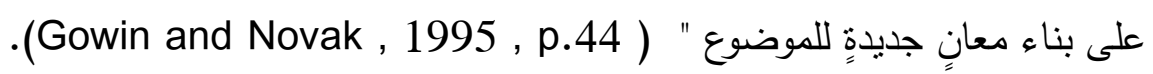

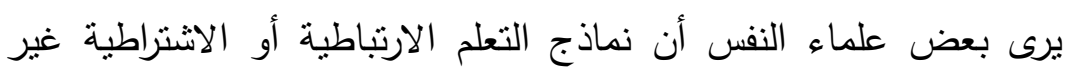

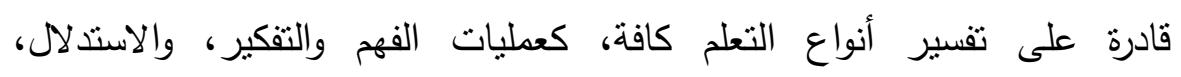

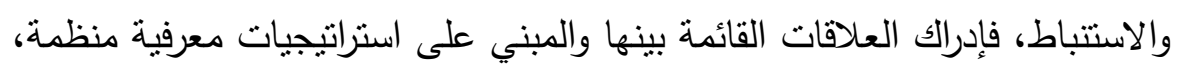

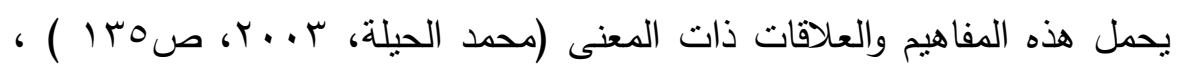

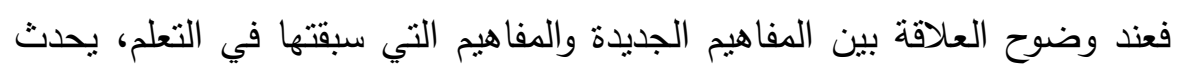

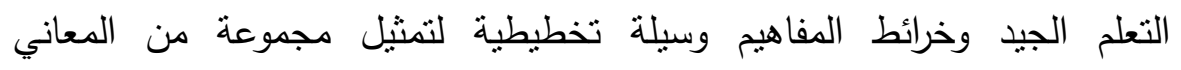
والعلاقات ذات المعنى بين المفاهيم على هيئة جمل مفتوحة.

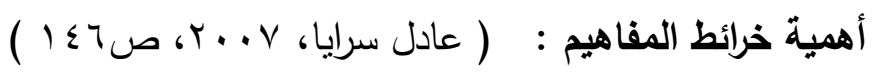

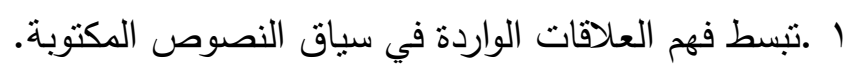

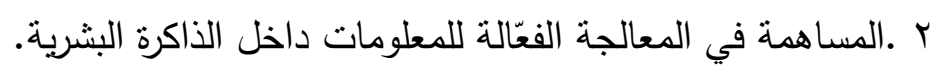

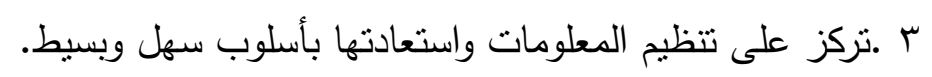
ـ .تتسيق المعلومات وتقديمها منسقة بشكل جذاب. ه .سرعة التواصل مع المعلومات والحقائق. 


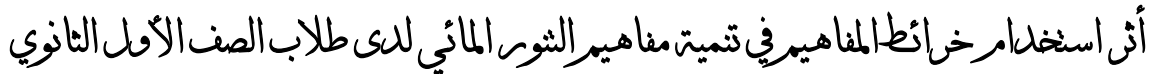

\section{كيفية تصميم خرائط المفاهيم :}

لا يمكن تصميم خريطة المفاهيم قبل التعرف على المفاهيم المراد إدخالها في

الخريطة مع أدوات ربطها الملائمة وعند تهيئة ذلك يتم الثروع بالتصميم حسب

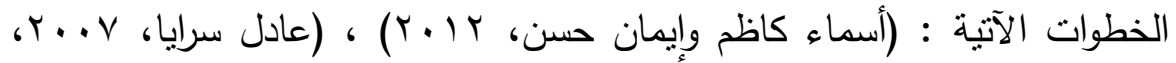
(Stwart , 1980, p .233-235 ) (101 ا ـ قراءة الموضوع المراد وضع خريطة المفاهيم لله بدقة وفهم وتمعن. r. تحديد المفهوم العام الثامل أو الموضوع المراد بناء له خربطة مفاهيم. r. تحديد المفاهيم المتفرعة المهمة والأساسية المرتبطة بالمفهوم العام. ع. تتظيم المفهوم العام الرئيس بشكل هرمي من الفكرة العامة إلى الأقل عمومية

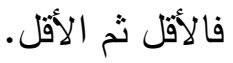

ه. وضع المفاهيم بأشكال هندسية ملائمة ممثلاً بـ( دوائر أو مربعات ). 7 . . تحديد العلاقات بين المفاهيم بوساطة الخطوط وأسهم الربط في الاتجاهات العمودية والأفقية. V. تحديد كلمة على كل خط من الخطوط والأسهم لتكون عنوانًا توضح طبيعة

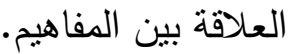
^. التأكيد من أن الخربطة تمثل عناصر الموضوع جميعها، ويجب وأَنْ تكون

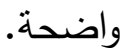

استخدامات خرائط المفاهيم :

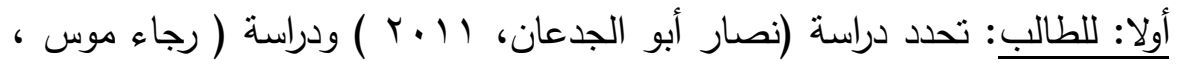
1 ا ب) دور الطالب فيما يلي: 
1- وسيلة من وسائل تلخيص المحتوى المعرفي وكتابة الملاحظات والنقاط

$$
\text { المهمة في المحاضرة. }
$$

r- اختصار كميات كبيرة من المعلومات واختزالها في مساحة محدودة

$$
\text { يمكن متابعتها بصريًا وذهنيًا. }
$$

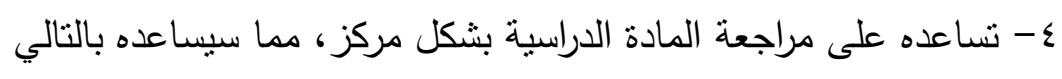

$$
\text { على تأدية الاختبارات. }
$$

0- العمل على ربط المفاهيم الجديدة بالقديمة، والتمييز بين الدفاهيم

$$
\text { المتشابهة. }
$$

צ- المساعدة على نتمية التحصيل الدراسي لدى الطلبة.

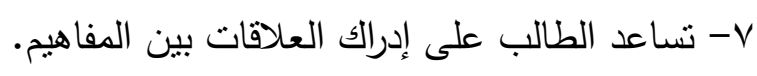
^- نساعد الطالب في أن يكون منظما ومصنفا للمفاهيم.

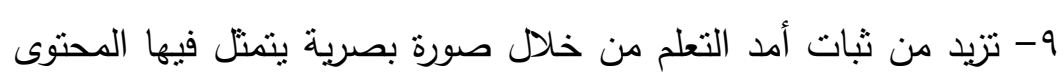
التعليمي مما يعين المتعلم.

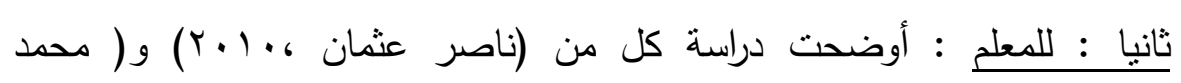

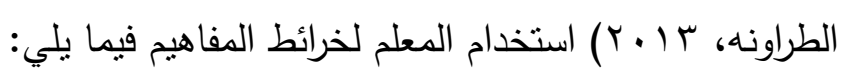

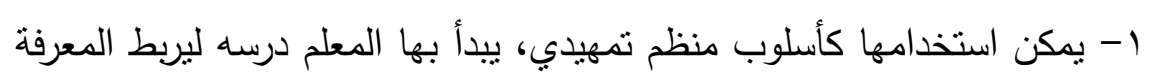
الجديدة بالمعرفة المخزونة في عقل المتعلم.

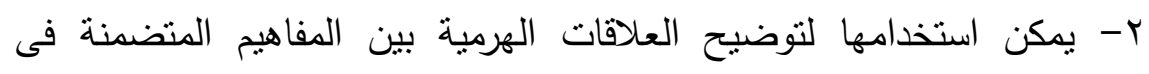

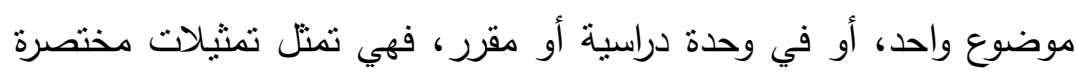

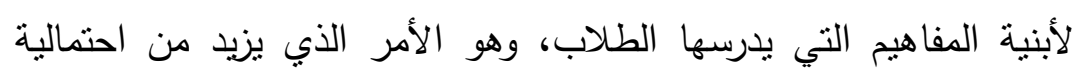
إسهامها في تسهيل تعلم هادف لتلاك الأبنية. r- نسهل حدوث التعلم ذي المعنى من خلال ربط المعرفة الجديدة بالمعرفة الانة

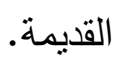




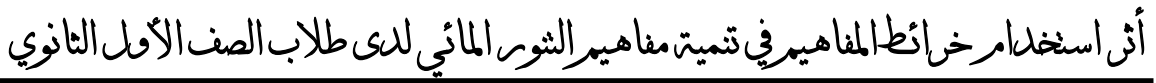

ع - تبرز صورة البنية الدفاهيمية لموضوع معين والعلاقات الموجودة بين مكوناته

بشكل بساعد المتعلم على الربط الواعي بينها.

0- تعمل كجسر بين الفجوات المفاهيمية الموجودة في البناء المعرفي للمتعلم

وتضيف مفاهيم جديدة إلى ذهن المتعلم لم يكن يتصورها سابقًا.

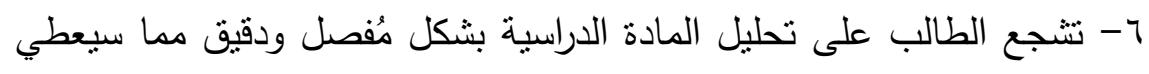

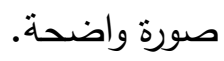

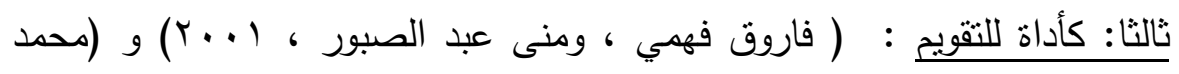

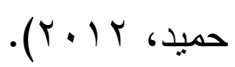

1- يمكن استخدام خرائط المفاهيم كأداة تنخيصية لتقويم تعلم الطلاب عن

الموضوع بدلا من الاختبارات النقليدية المكتوبة.

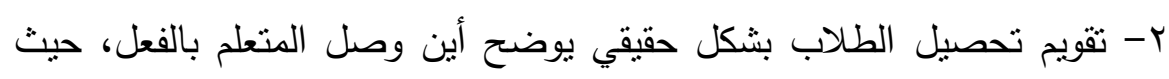
تبين كية الدفاهيم لاى الثخص والعلاقات بينها، وما إذا كانت هذه العلاقة

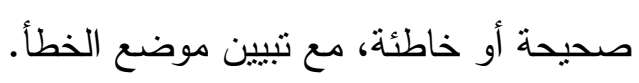

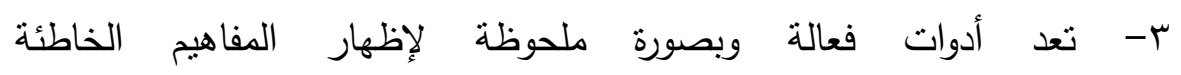
misconceptions إدراك الخطأ، أو تحديد المفاهيم المفقودة التي سبيت الفهم الخطأ، أو تحديد

العلاقات الخاطئة التي سببت الفهم الخطأ.

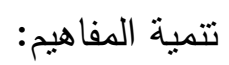

تتمية المفاهيم هي مدى معرفة المتعلم بما يمثل المفهوم ومن لا يمثلك من

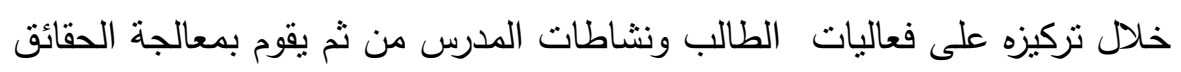

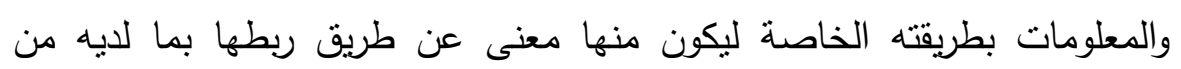
معلومات قبل أن يقوم بحفظها في ذاكراته.

. YVT. 
يرى (الثربيني) أن عملية تكوين المفهوم تسبق عملية اكتساب المفهوم

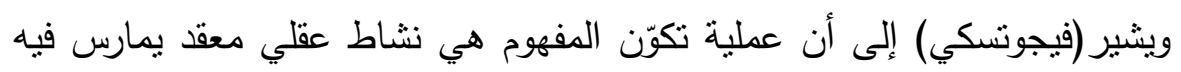

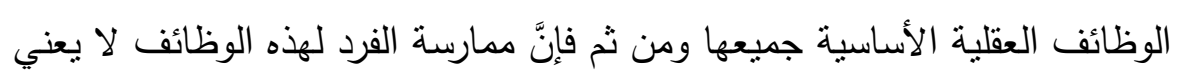

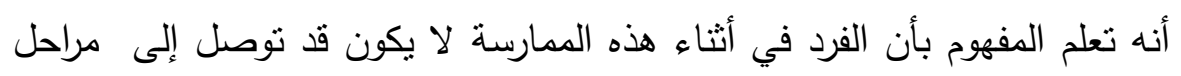

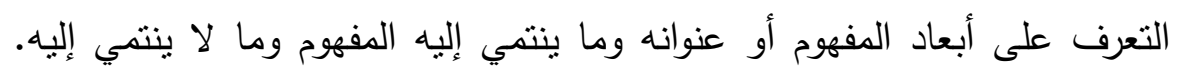

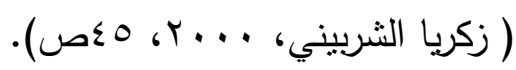

$$
\begin{aligned}
& \text { أهمية تعلم المفاهيم: زئن }
\end{aligned}
$$

يعُد تعلم الطلبة للمفاهيم العلمية من أكثر جوانب التعلم فائدة في الحياة

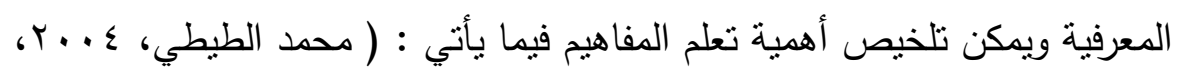

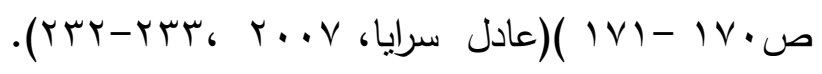

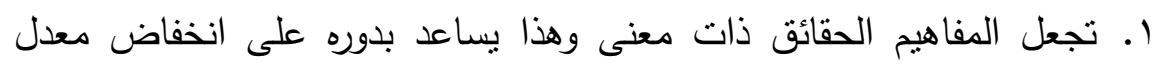
النسيان.

r. تقلل المفاهيم من الحاجة إلى إعادة التعلم عند مواجهة أي جديد فأنها نساعد على انتقال أثر التعلم. r. بؤدي تعلم المفاهيم إلى زيادة اهتمام المتعلم بالمادة وكما تزيد عادة من دوافعهم لتعلمها وتحفز البعض منها إلى التعمق في دراستها والتخصص فيها.

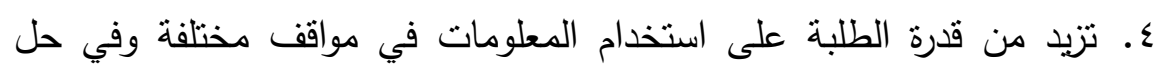

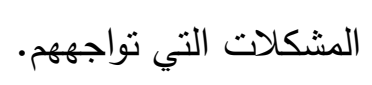

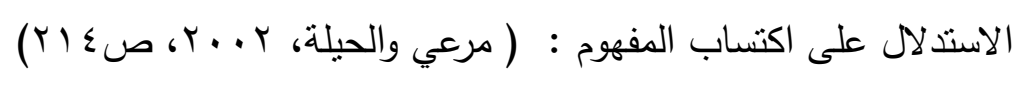

إنَّ قياس اكتساب المفاهيم شأنه شأن أي جانب أخر من عملية التعلم

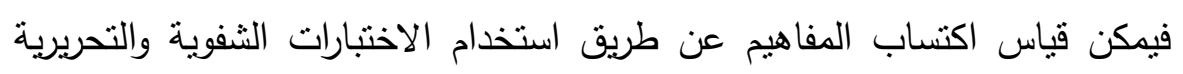
. TVV. 


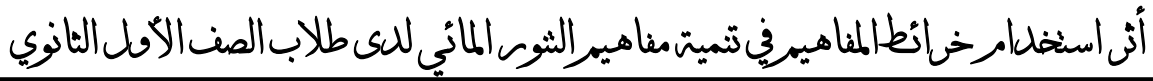

بأثكالها المختلفة ومن خلال الملاحظة والمناقثة مهما تكن طريقة القياس يمكن

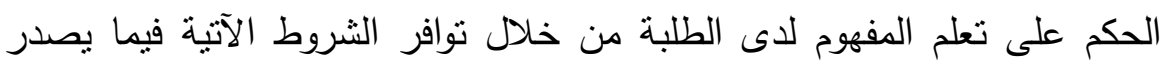

$$
\text { عنهم من أداء : أعل }
$$

ا. أن يقوموا بالتعبير لفظيًا عن المفهوم أي أن يعرفوا الدفهوم من أبعاده الدختلفة

$$
\text { وما يدل عليه. }
$$

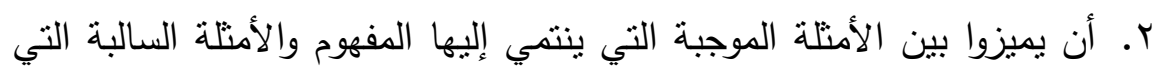

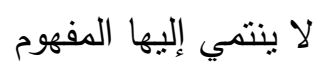

r. أن يستخدموا المفهوم الذي تعلموه وهذا ما بسمى بإنتقال أثز التعلم، إذ لا قيمة لمعرفة الطلبة للمفهوم ما لم يكونوا قادرين على الافادة منه في مواقف جديدة. ع. أن يدركوا العلاقة الهرمية التي نتربط بين الدفهوم الذي نعلموه وغيره من

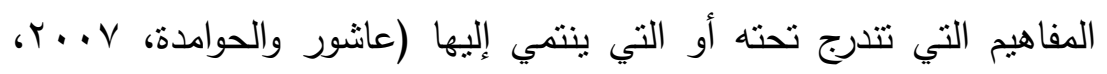
ص (r9 (r)

مراحل تعلم المفهوم : يميز أوزوبل بين مرحلتين في تعلم المفاهيم هما :

$$
\text { المرحلة الأولى : تكوين المفاهيم }
$$

هي عملية الاكتثاف الاستقرائي للخصائص الفاصلة لفئة المثيرات وتتدمج

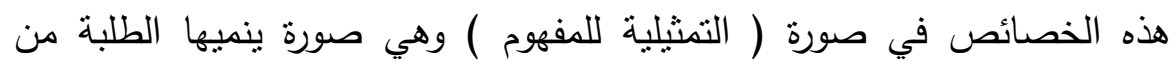

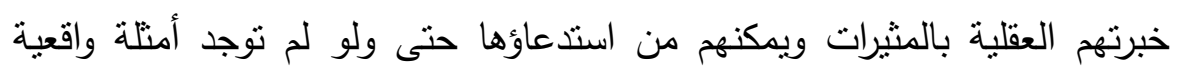

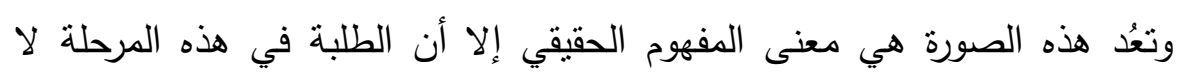
يسنطيعون تتمية المفهوم على الرغم من أنهم قد تعلموه.

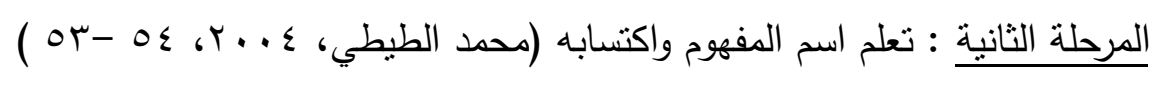


في هذه المرحلة يتعلم الطلبة معنى اسم المفهوم وهو نوع من التعليم التمثيلي حيث يتعلم الطلبة أن الرمز المنطوق أو المكتوب يمثل المثل المفهوم الذي لئي

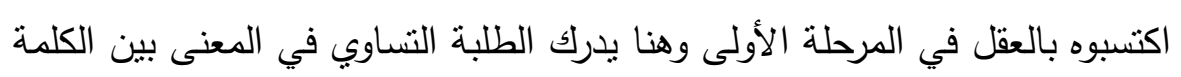
والصورة التنثيلية وفي هذه الحالة تكتسب كلمة المفهوم المعنى الدلالي وهذه المرحلة تقابل نوع التعلم التمثيلي أو الصوري وهو من أنواع التعلم بالتلقي.

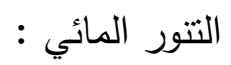

ولما كان الماء هو شريان الحياة في مصر والعالم العربي بل والعالم كله،

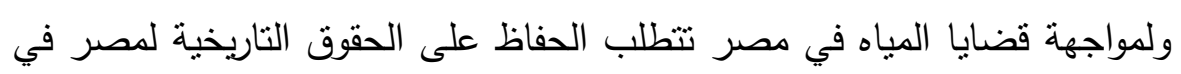

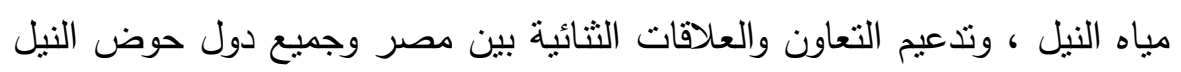

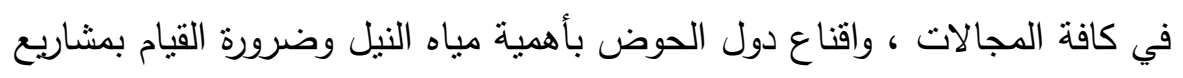

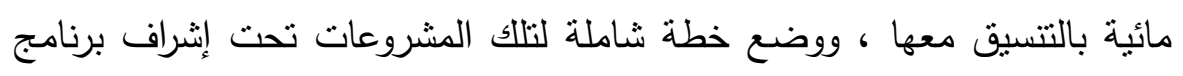
الأمم المتحدة للتتمية.

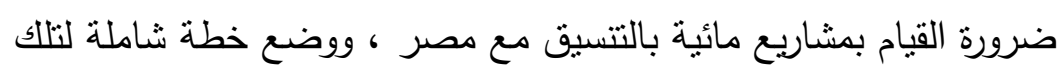

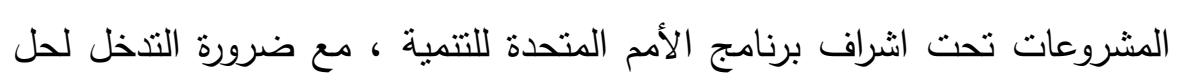

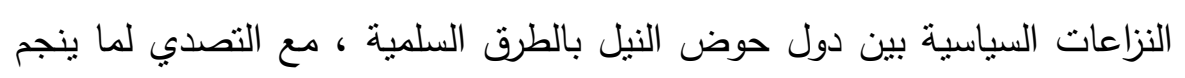

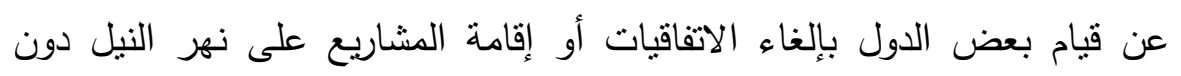

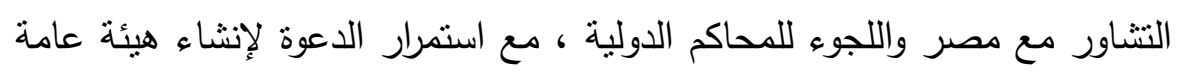

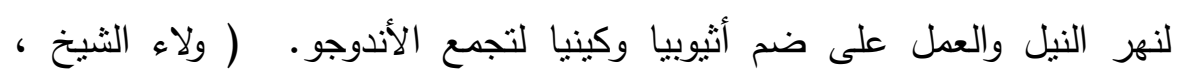

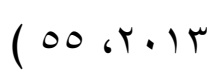

وكذلك الاهتمام بترشيد استخدام المياه في الأنشطة البشرية المختلفة

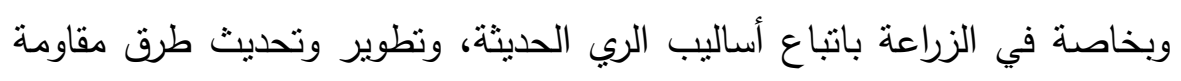

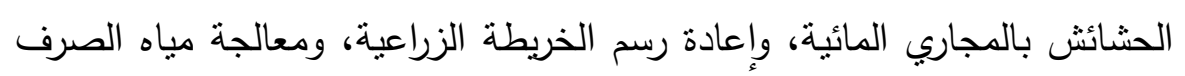
الزراعي بالتقنيات الحديثة وإعادة استخدامها. . rVq. 


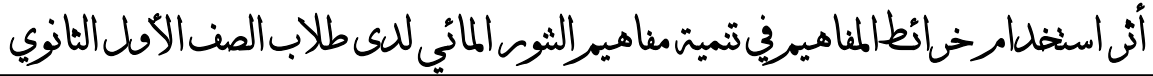

وكنلك الاهتمام بزيادة الموارد المائية غير التقليدية المتمنلة في إعادة استخدام

مباه الصرف الصحي والصناعي والزراعي بعد المعالجة الدقيقة لها، واستخدام المياه شبه المالحة في الرى، وكذللك تحلية مياه البحر مع استخدام اساليب التراعياه

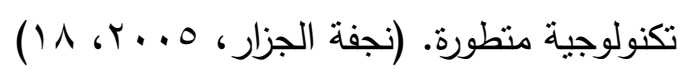

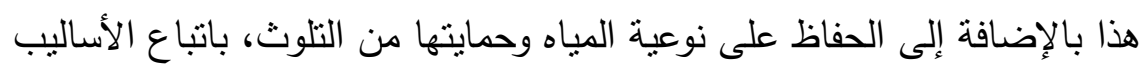
والاجراءات المناسبة، والاعتراف بندرة المياه وتوعية الجماهير بخطورتها، وتكثيف

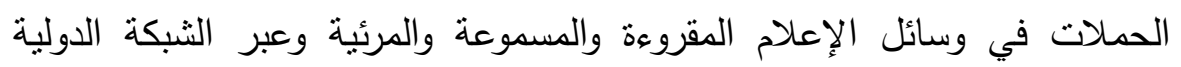
للمعلومات لنوعية الناس بخطورة ندرة المياه، وكذلك عقد الندوات والمؤتمرات بصفة الإنة

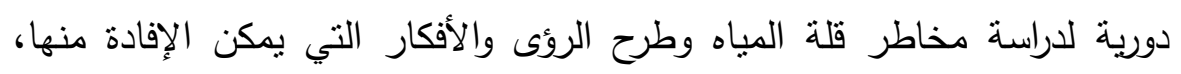

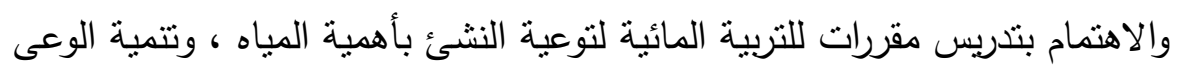

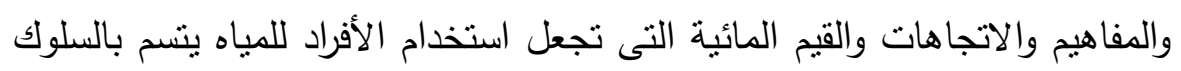

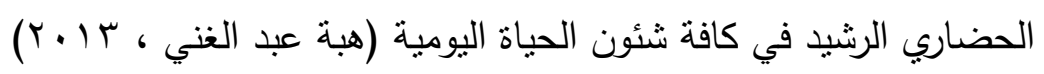

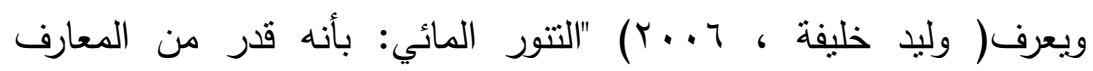

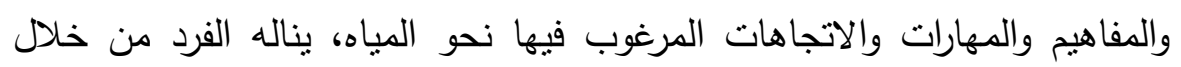

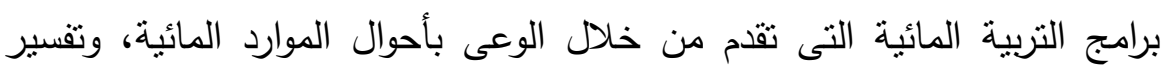

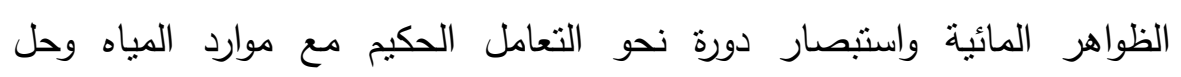
مشكلاتها.

مراحل تنمية التنور المائي: - ماتيا. تعددت مراحل تتمية التتور عموما، وذلك لكثرة الأدبيات التي تمت في هذا

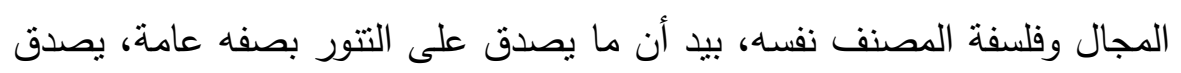

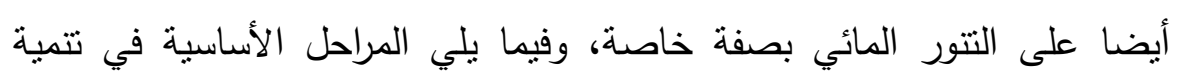

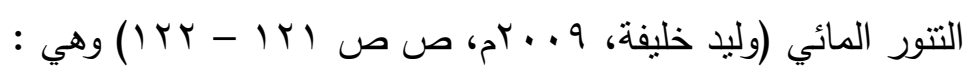
. . $\Lambda$. 
أ- المرحلة التمهيدية: وفيها ينبغي تحديد ما لدى التلاميذ من معارف ومفاهيم وسلوكيات متصلة بموضوع الوعي، فلا يصح تقديم خبرات جديدة للتلاميذ إلا إذا اتضحت الرؤية لما يوجد لديهم من معلومات سابقة، وتوكيدا لفكرة النتائج المنطقي. ب- مرحلة التكوين: يتم في هذه المرحلة تحديد المداخل المناسبة لتكوين الوعي

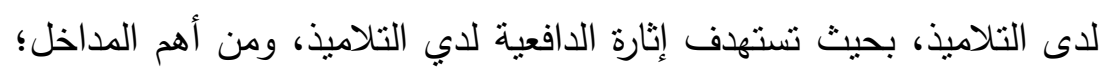
الاهتمامات والحاجات والآمال التي يشعر بها التلاميذ وتجذب انتباههم. ج- مرحلة التطبيق: وفيها تتاح المواقف كما وكيفا للتناميذ كي يطبقوا ما سبق

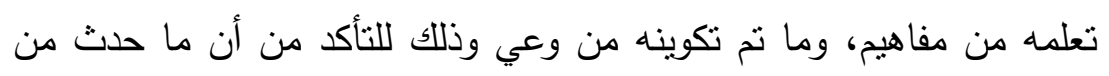
تعلم له آثار باقية ومؤثرة في عقل ووجدان وسلوكيات الفرد، فما سبق تعلمه ندانه لابد أن يجد الفرصة للتطبيق والممارسة.

د- مرحلة التثييت: وهذه المرحلة خاصة بعملية التوسيع لما سبق تعلمه، وتكوينه من المفاهيم والتأكد من تأثيرها في مستويات الوعي لدي التلاميذ، وفي هذه المرحلة على المعلم أن يخطط مواقف عديدة ومناسبة من شأنها أن تعزز وتدعم ما سبق تعلمه.

هـ- مرحلة المتابعة: هي مسألة تتطلب من المعلم أن يخطط أنشطة جديدة يشارك

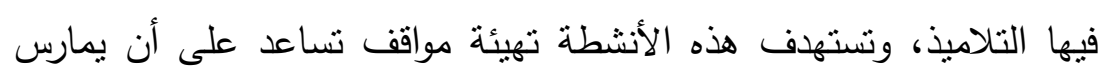

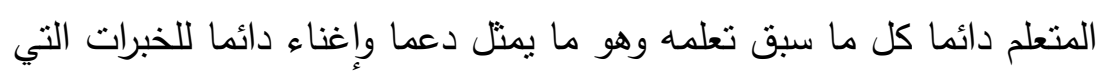
يمر بها المتعلم. دور معلم الجغرافيا في التنور المائي: بالنظر إلى دور المعلم فى العملية التعليمية وما يجب أن يقوم به، ونوع

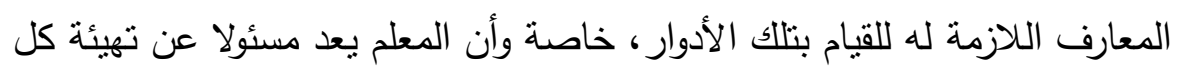

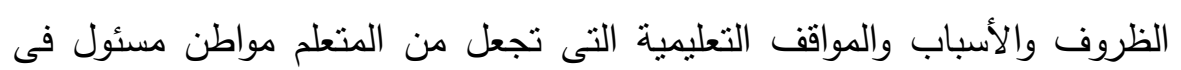
. Y人). 


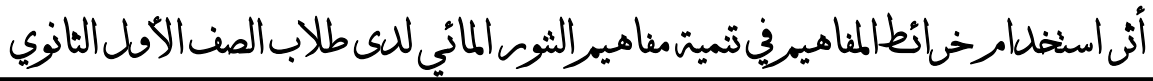

ظل الظروف الحياتية التى يعيها والتحديات البيئية التى يواجهها مجتمعه، فإنه

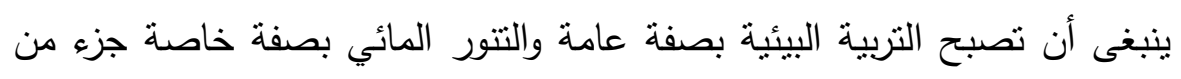

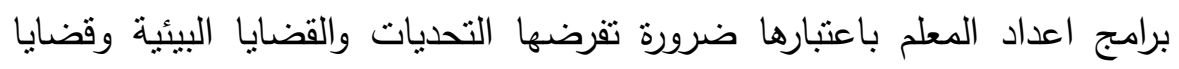

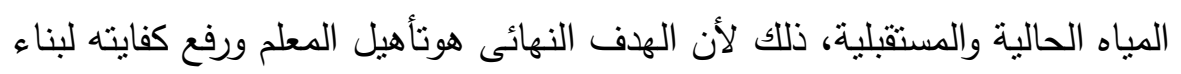

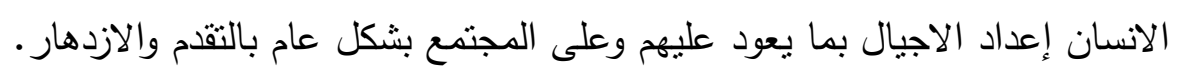

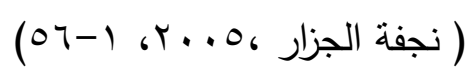

أهمية التنور المائي لاى طلاب المرحلة الثانوية :

ولطلاب المرحلة الثانوية خصائص وسمات مميزة قد نسهم امكانية تتمية

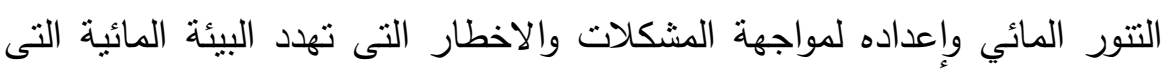

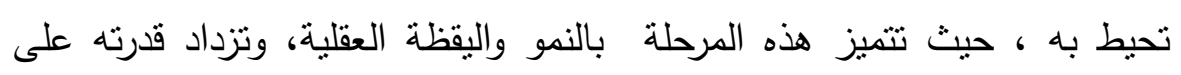

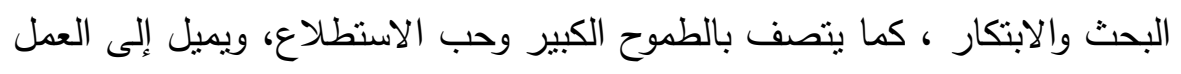

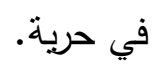

أكدت العديد من الدراسات على أهية تتمية التتور المائي، من خلال تتمية

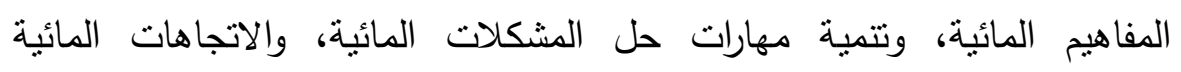

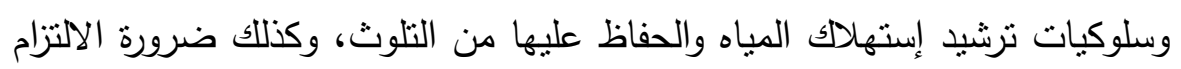
بأخلاقيات التعامل مع المباه، وغيرها من الجوانب التى تظهر أهمية تتمية التنور

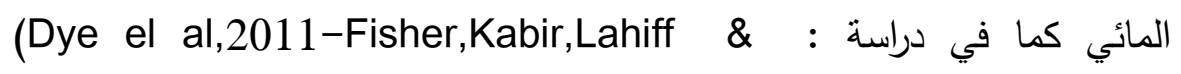
Maclachlan,2011- Salunke,Devendrappa \& Sidram,2011Garcia, et al., 2013)

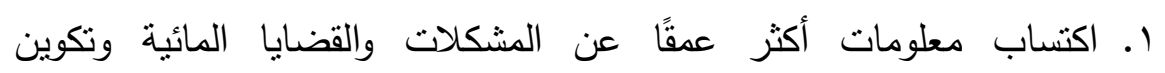
الاتجاهات والسلوكيات المرغوب فيها، واللازمة للحفاظ على المياه، والعمل

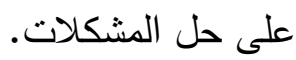
. YAY. 
r. أن إدراك الفرد واحساسة العميق بالمشكلات المائية، ينمى لديه المسئولية نحو

$$
\text { مصادر المباه، ويحافظ عليها من الهدر والتلوث. }
$$

r. أن نمو التتورالمائي عند الأفراد بأبعاده المختلفة، يتيح الفرصة لتحقيق أقصى لتصى

استفادة من الموارد المائية مما يعود على المجتمع بالخير والرخاء.

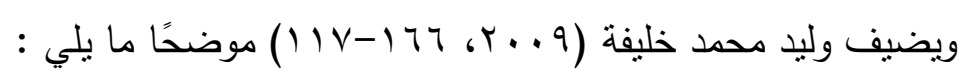

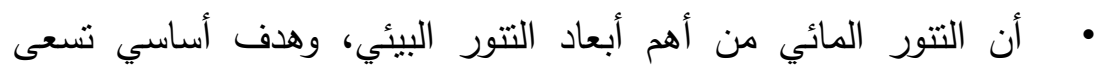

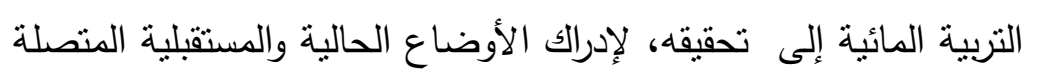

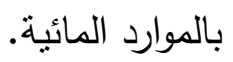
• أنه بسهم فى تكوين الاتجاهات المرغوبه نحو الحفاظ على المياه وحسن

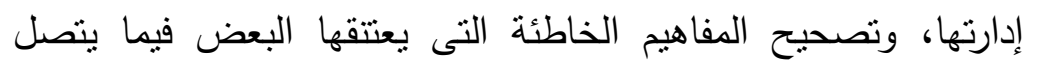
بكمية ونوعية المياه. • أنه بسهم في تحقيق جانب كبير من الأمن المائي، والذى بعد بعدًا من بند

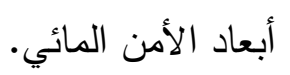
• اكساب أفراد المجتمع السلوكيات السليمة المتصلة بالتعامل الحكيم مع العي

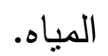

• ضمان الوقاية من المشكلات المائية العديدة التي ظهرت بسب جهل الإنسان بالوضع الحرج لقضية المياه في العالم. • التتور المائي أساس مهم في تتمية وتحقيق الأمن القومي لأى دولة. 


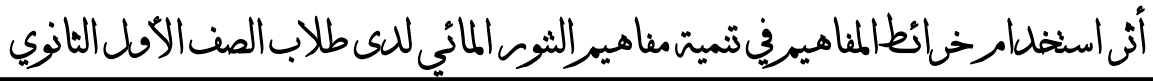

هناك من الدلائل ما يفيد سوء استغلال الإنسان لبيئته المائية متمثلاً في

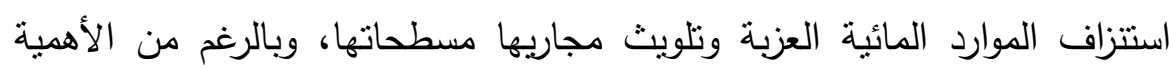

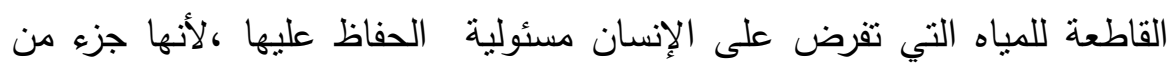

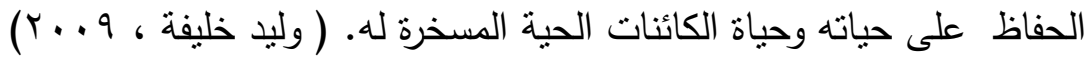
في ضوء ما سبق يمكن توضيح أهمية التتور المائي لدى طلاب المرحلة الثانوية:

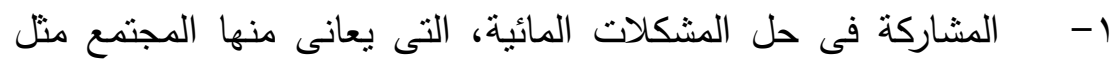
سوء استهلالك المياه وتلوثها. r- ينمى لديهم الإحساس بالمسئولية نحو حماية الموارد المائية، والحفاظ

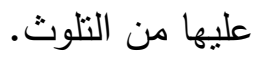
r- يعمق شعورهم بقيمة المياه فى حياتهم، وينمى لديهم الاحساس الوطنى وضرورة الحفاظ على الموارد المائية، وبذل كل ما هو غال ورخيص

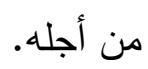

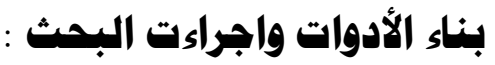

منهج البحث: اعتمد البحث على الدنهج الوصفي التحليلي، وذللك بتحليل محتوى

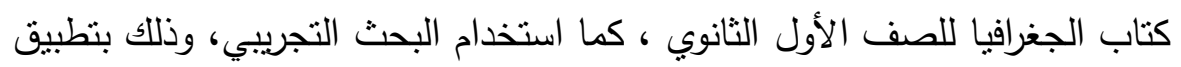

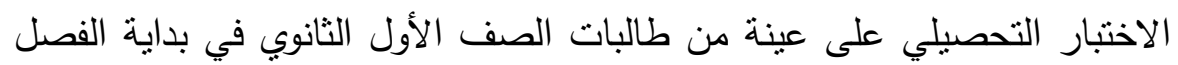

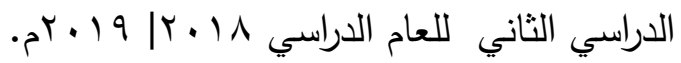
عينة البحث: تكونت عينة البحث من: - - مقرر الجغرافيا للصف الأول الثنانوي. - - عدد ·r من طالبات الصف الأول الثانوي.

. Y^乏. 
وتم اختيار مجموعة البحث عينة عنقودية عشوائية من مدرسة السويس

الثنانوية بنات.

أدوات البحث: استخدم البحث الأدوات التالية، وهي من إعداد الباحثة:

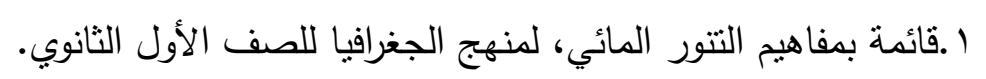
r.اختبار تحصيلي يتتاول مفاهيم التنور المائي. r.دليل المعلم (باستخدام استراتيجية خرائط المفاهيم لتتمية مفاهيم التتور المائي ).

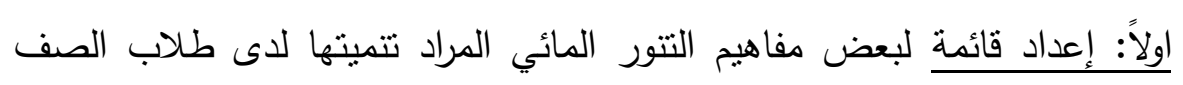
الأول الثنانوي الأباد

للإجابة عن النساؤل الأول من تساؤلات البحث وهو :

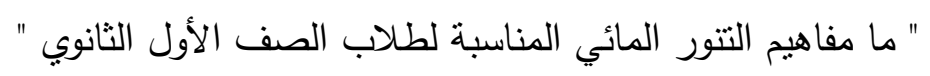

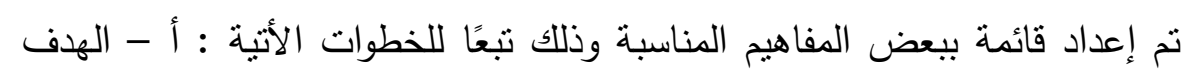
من القائمة :

تستهدف تحديد مفاهيم التتور المائي التي يجب أن يتضمنها منهج الجغرافيا للصف

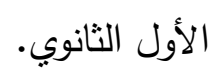

ب- مصادر انتقاق القائمة : نم انتقاق القائمة من مصادر متعددة هي :

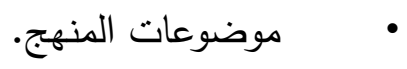

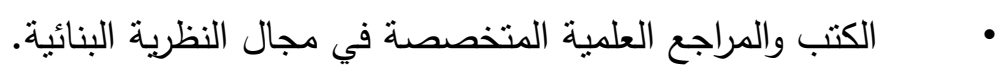

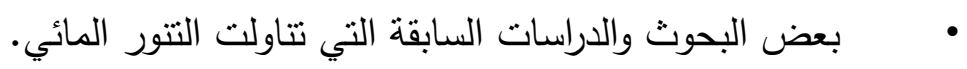

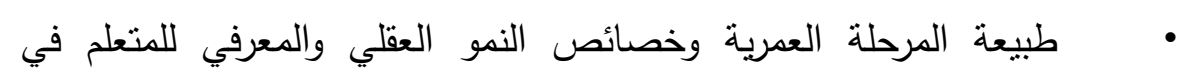
الصف الأول الثانوي. ج - إعداد الصورة الأولية للقائمة :

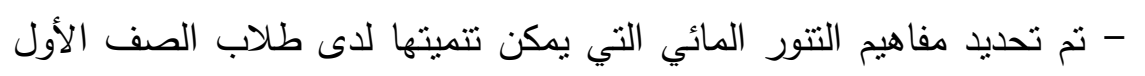
الثانوي. . TNO. 


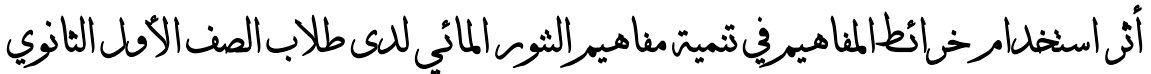

د- ضبط القائمة : تم عرض الصورة الأولية لقائمة المفاهيم على المحكمين بهدف معرفة أراءهم. هـ - الصورة النهائية للقائمة : في ضوء ما أسفرت عنه نتائج الخطوة السابقة تم إجراء التعديلات المقترحة أصبحت القائمة في صورتها النهائية.

\begin{tabular}{|c|c|c|c|c|c|c|c|c|}
\hline \multicolumn{3}{|c|}{ الاول الثانوي ملثتها لطلاب الصف } & \multicolumn{3}{|r|}{ ملاحظات } & \multirow{2}{*}{ 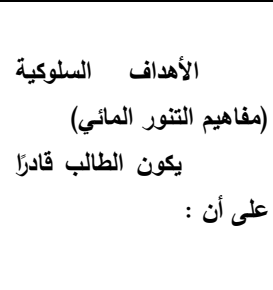 } & \multirow[t]{2}{*}{ p } & \multirow{2}{*}{ 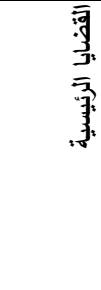 } \\
\hline 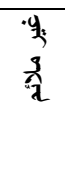 & 蛹 & 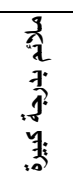 & $\begin{array}{l}\text { 年; } \\
\text { 条 }\end{array}$ & 㝵 & 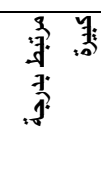 & & & \\
\hline & & & & & & 'يعرفية المقصود بالموارد & 1 & $\begin{array}{l}\overline{9} \\
\overline{3}\end{array}$ \\
\hline & & & & & & يذكر المقصود بتلوث المياه. & r & 裹 \\
\hline & & & & & & 'يعرفي المقصود بالفقر & $r$ & 襄 \\
\hline & & & & & & المائي. تعريف لمفهوم التتور & $\varepsilon$ & 量 \\
\hline & & & & & & 'يعرف ظاهرة الجفاف. & o & \\
\hline & & & & & & يكتب القصود بالانديجو & 1 & \\
\hline & & & & & & يكتب مفهوم حوض النهر & $\mathrm{v}$ & \\
\hline & & & & & & 'يعرف مفهوم الأمن المائي & $\wedge$ & \\
\hline & & & & & & 'يُعنف مفهوم الاستمطار & 9 & \\
\hline & & & & & & المائية المقصود بالتسعيرة & 1. & \\
\hline
\end{tabular}

تصميم أدات القياس : الاختبار المفاهيم.

إعداد اختبار تحصيلي لمفاهيم التتور المائي : 
وقد ثم ذلك وفقًا للخطوات التالية :

- - مديد نوع أسئلة الاختبار •

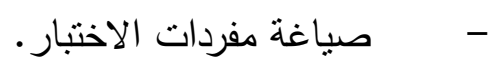

- - مصياغة التعليمات.

- - مبط الاختبار

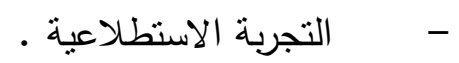

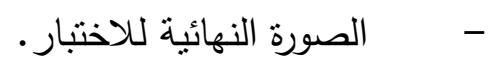

المعالجة الاحصائية: اختبار صحة الفرض الأول :

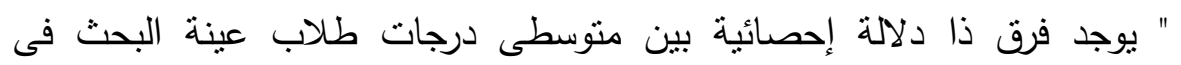
التطبيقين القبلي والبعدي لاختبار التحصيل لصالح التطبيق البعدي." ولاختبار صحة هذا الفرض تم وصف وتلخيص بيانات البحث بحساب رالمتوسط الحسابي، الانحراف المعياري، وقيمة ( ت )؛ لدرجات عينة البحث في التطبيقين القبلي والبعدي لاختبار التحصيل ما يوضحها

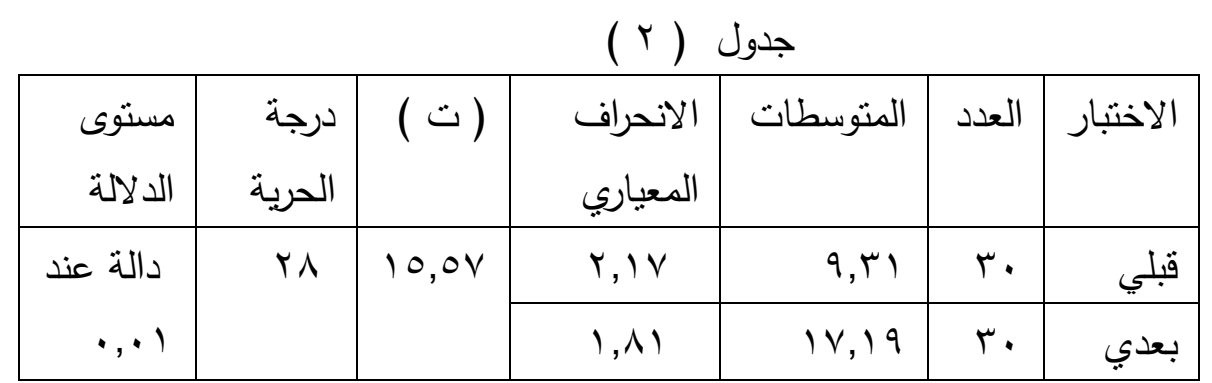

يتضح من الجدول السابق أن قيمة " ت " المحسوبة بالنسبة للاختبار التحصيلي بلغت (10,0V) تجاوزت قيمة " ت " الجدولية عند درجة حرية (Y) ومستوى بله دلالة (1 (., ) مما يدل على وجود فرق حقيقي بين متوسطي درجات التطبيقين لصالح التطبيق البعدي ( ذا المتوسط الأكبر). 


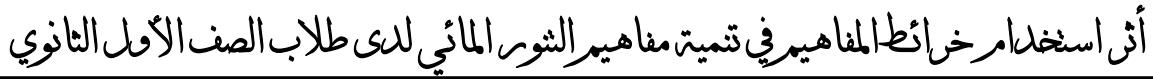

ا فاعلية خرائط المفاهيم في تتمية مفاهيم التتور المائي بوصفها استراتيجية تلبي جانبًا مهمًا من دعوات المختصين بضرورة التطور التربوي واستعمال الطرق الحديثة

$$
\text { في التدريس. }
$$

r •إِنَّ التدريس وفق خرائط المفاهيم ساعد الطالبات على إعادة تنظيم المفاهيم في البنيه المعرفية، من خلال ربط المفاهيم السابقة بالمفاهيم الجديدة. r ـإِنَّ خرائط المفاهيم من الأدوات المفيدة في تعزيز التحصيل الدراسي وتدعيمه وتقويته، تضفي المعنى على المفاهيم، وتعمق فهم الطالبات لمفاهيم التتور المائي ع. .إِنَّ تدريس المفاهيم التتور المائي على وفق خرائط المفاهيم ساعد الطالبات على ونى التعرف على اسم المفهوم وذكر خصائصسه وتطبيقه بصورة صحيحة، وهذا يفسح المجال للطالبات القيام بعطيات عقلية راقية تساعدهن على اعطاء أمثلة على وهلى وهنئ المفهوم من خلال خبرتهن السابقة، وهذا بدوره يؤدي إلى ترسيخ المفهوم واكتسابه.

في ضوء النتائج التي تمخضت عن البحث الحالي يمكن للباحثة أن تستتتج ما يلي: ا لإنَّ خرائط المفاهيم أثنتت فاعليتها ضمن الحدود التي أجريت فيها الدراسة الحالية في اكتساب طالبات الصف الأول الثانوي لمفاهيم التتور المائي. r •إِنَّ خرائط المفاهيم تتمي القدرة لدى المتعلم على تعريف أغلب مفاهيم التتور المائي وتطبيقاتها في حياتتا اليومية. r ـلابد من مواكبة التطور المعرفي من خلال اتباع أساليب تدريسية حديثة واستراتيجيات ناجحة من أجل اخراج المتعلم من قوالب طرق التدريس التقليدية. 
؛ .يثجع التدريس باستخدام خرائط المفاهيم المتعلم على حرية إثارة الأسئلة وإبداء

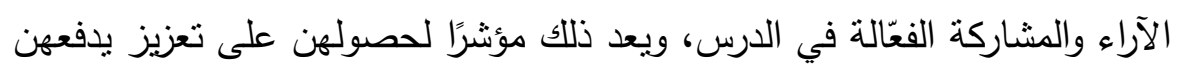

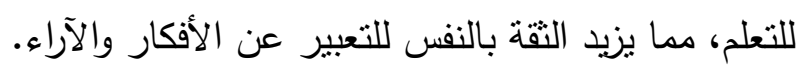

\section{التسوصيات :}

في ضوء نتائج البحث الحالي توصي الباحثة بالتوصيات الآتية:

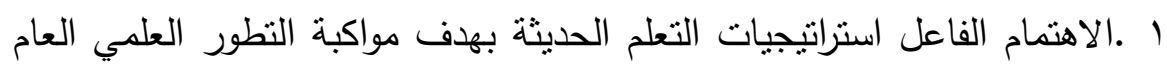
ونتمية القدرات الذهنية لاى المتعلم.

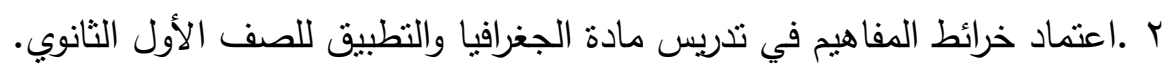

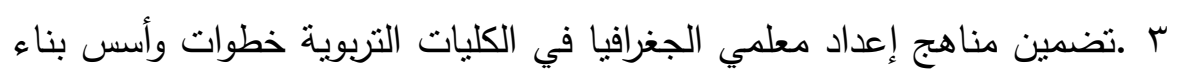
خرائط المفاهيم وتدريبهم على كيفية تصميمها وأعدادها واستخدامها. ؛ .حث معلمي الجغرافيا على الاهتمام بالمفاهيم بتتمية مفاهيم التتور المائي بدلاً من الحفظ الأصم.

المتترحات:

في نهاية البحث تقترح الباحثة: أ اجراء دراسة ممائلة للاراسة الحالية لصفوف ومراحل دراسية أخرى (ابتدائية، اعدادية). r ـاجراء دراسة مماثلة للاراسة الحالية حول أثر استخدام خرائط الدفاهيم في تتمية

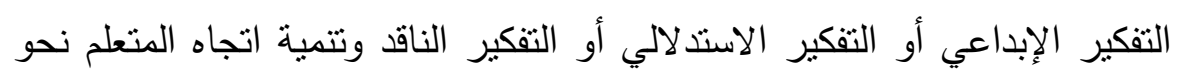

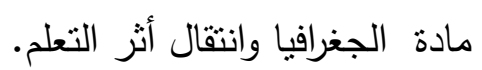
r • إجراء دراسة مماثلة للاراسة الحالية حول أثر استخدام خرائط المفاهيم في تتمية

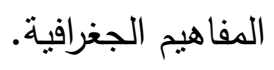
. Y^9. 


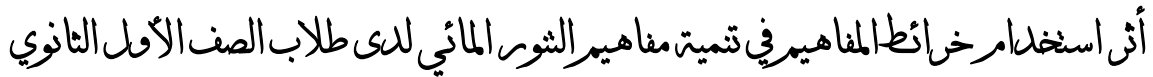

ع .اجراء دراسة ممائلة للاراسة الحالية لمعرفة أثر استخدام خرائط الدفاهيم على دائ المتأخرين دراسيًا الذنين يعانون من صعوبات في التعلم.

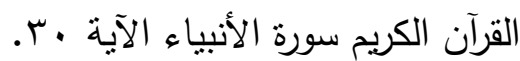

إبراهيم محمد محمد ( (... ץ). الوعى المائي لدى الطلاب المعلمين بكلية التربية

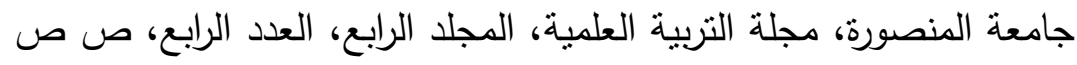
$.0 Y-\varepsilon r$

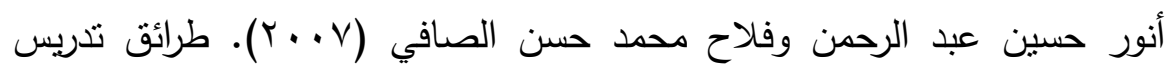

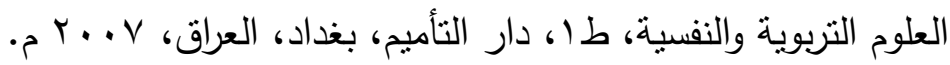

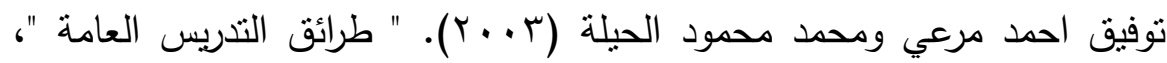
طا، دار المسيرة، للنشر والتوزيع، عمان، الأردن.

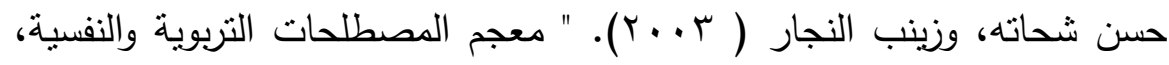

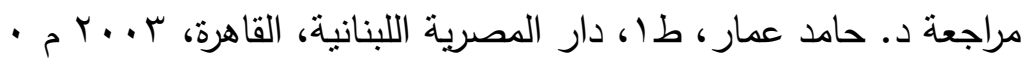

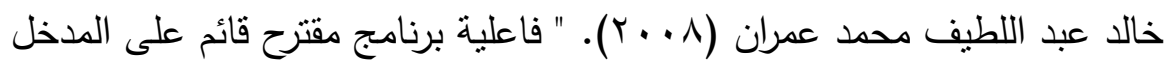
القصصي في تدريس الدراسات الاجتماعية لتحقيق بعض أهداف التربية المائية لدى تلاميذ الصف الخامس الابتدائي، المجلة التربوية، كلية التربية،

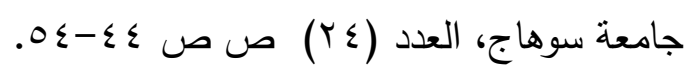

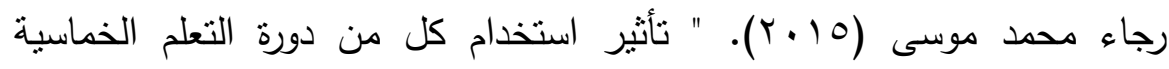

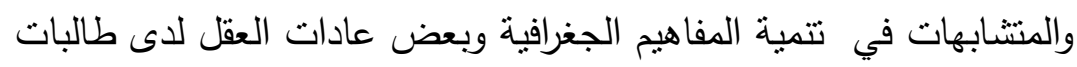


الصف السابع الأساسي" رسالة دكتوراة، كلية البنات للأداب والعلوم التربوية ، جامعة عين شمس.

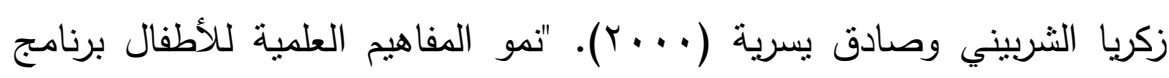
مقترح وتجارب الطفل ما قبل المدرسة "، طا، دار الفكر.

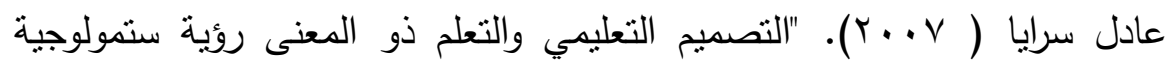

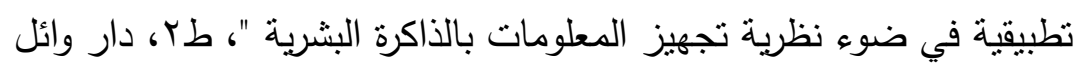
لللنشر والتوزيع، عمان، الأردن.

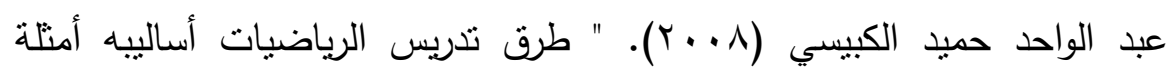

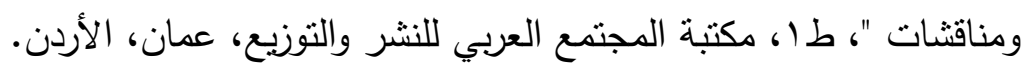

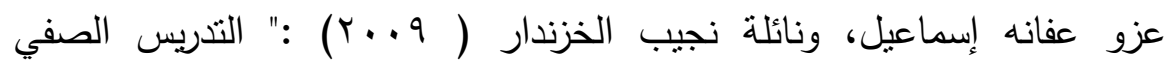

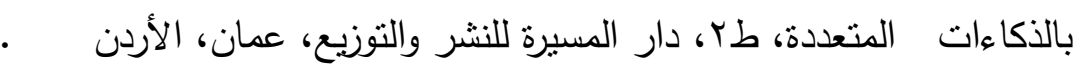

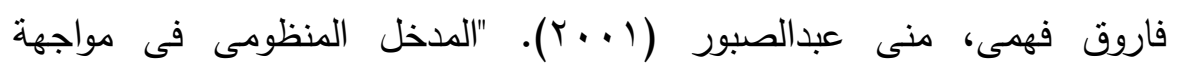

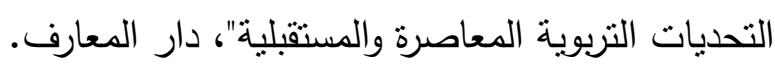

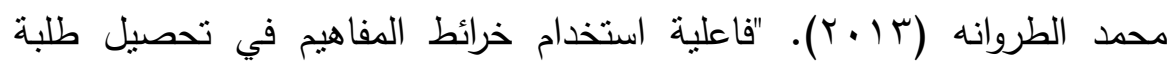

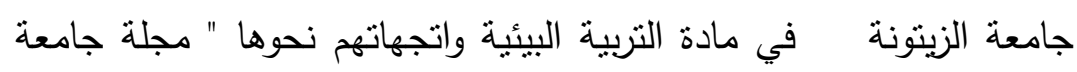
القسس ، الاردن ، عدد ع الت.

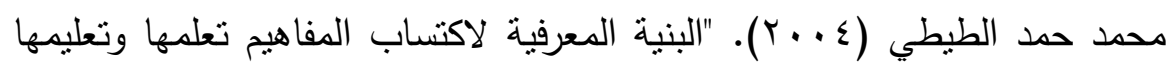

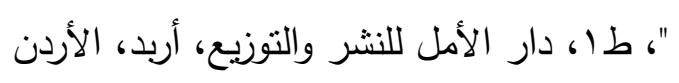

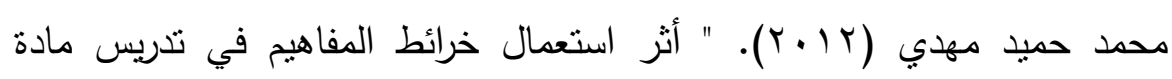

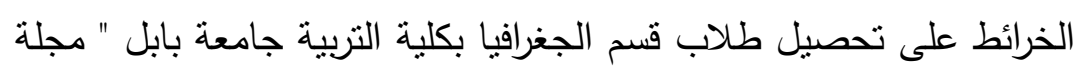

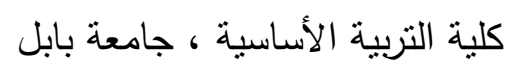

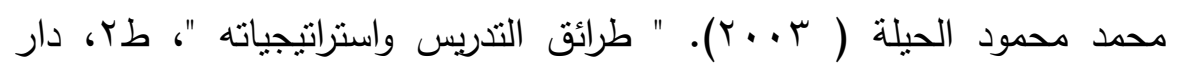

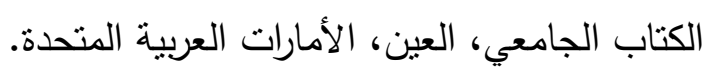




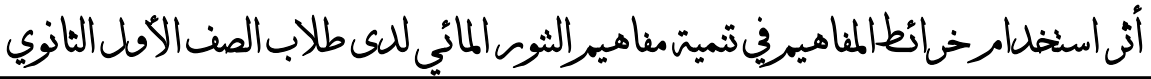

محمود أبو زيد (991)). المياه مصدر التوتر في القرن الحادي والعشرين، القاهرة، مركز الأهرام للترجمة والنشر · مباه

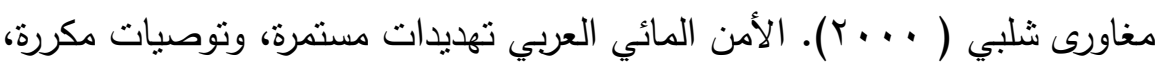
المؤتمر الدولي الثامن، الأمن المائي العربي، القاهرة، مركز الدراسات العربي لإني الأوربي

ناصر بن عثمان بن راشد (· (ب). " أثز استخدام خرائط المفاهيم في تدريس مادة الجغرافيا في تحصيل تلاميذ الصف الأول المنوسط واتجاهاتهم نحو المقرر الدراسي" ، رسالة ماجستير ، كلية التربية ، جامعة الملك سعود.

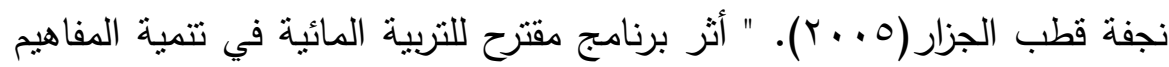

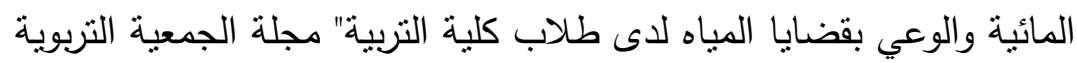

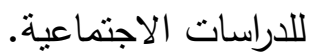
نصار أبو الجديان (1) (1). " فعالية استراتيجية الخرائط الدفاهيمية في تدريس مادة الجغرافيا في تتمية مهارات التفكير الناقد لاى طلاب الصف الثامن

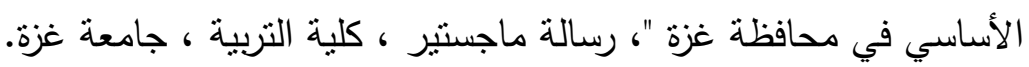

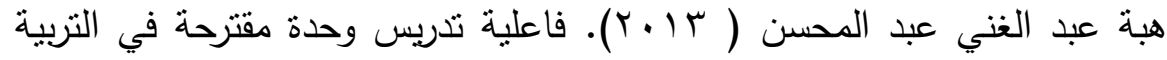
المائية باستخدام استراتيجية التعلم المتمركز حول المشكلة على تتمية التتور المائي وبعض عمليات العلم الاساسية لتلاميذ الصف الخامس الابتدائي، رسالة ماجستير ، كلية التربية، جامعة المنيا

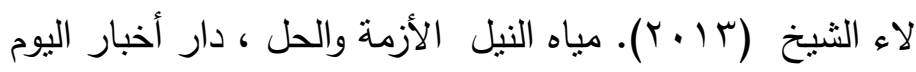

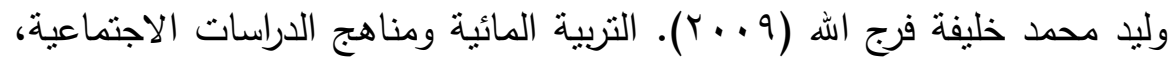
دار العلم 
وليد محمد خليفة فرج الله (· • ( ). فاعلية برنامج مقترح في الجغرافيا قائم على

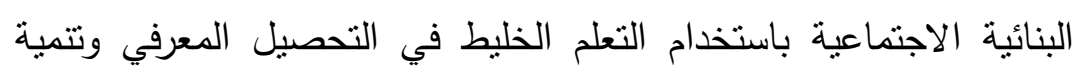

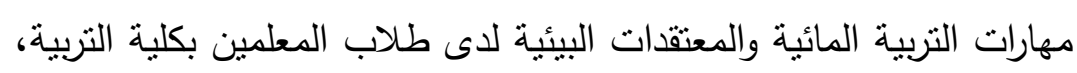
رسالة دكتوره، كلبة التربية، جامعة سوهاج.

Garelt, Dawn. (2011). Constructivism Deconstructed In Science Teacher Education 'Australian Journal of Teacher Education Vo36, N6

Madalla, A.(2004). Environmentalism in the middle east: attitude toward preservation, conservation and grass tools ecosystem management in Bahrain, and Saudi Arabia, Ph.D., state university

Novak, J. D , and Gowin (1995). "Learning How to Learn, - 29

combridge university press, Now York.

Novak, J. D. and Musonda D (1990). Atwelve year longitudihal Study of Science concept", Learning American Educational Research.

Stwart, James 1980, Techniques For Assessing and Representing Information in Cognitive, Structor, Science Education, Vol.(64).No 